\title{
Single-step genomic evaluation improves accuracy of breeding value predictions for resistance to infectious pancreatic necrosis virus in rainbow trout
}

\author{
Grazyella M. Yoshida $^{\mathrm{a}, \mathrm{b}}$, Roberto Carvalheiro ${ }^{\mathrm{b}}$, Francisco H. Rodríguez ${ }^{\mathrm{a}, \mathrm{c}}$, Jean P. Lhorente ${ }^{\mathrm{d}}$, \\ José M. Yáñez ${ }^{\mathrm{a}, \mathrm{d}, \mathrm{e}, *}$ \\ ${ }^{a}$ Facultad de Ciencias Veterinarias y Pecuarias, Universidad de Chile, Av Santa Rosa 11735, La Pintana, Santiago 8820808, Chile \\ b Animal Science Department, Universidade Estadual Paulista "Júlio de Mesquita Filho" (UNESP), Faculdade de Ciências Agrárias e Veterinárias (FCAV), Campus \\ Jaboticabal, Via de Acesso Prof. Paulo Donato Castellane, 14884-900 Jaboticabal, Brazil \\ ${ }^{\mathrm{c}}$ Facultad de Medicina Veterinaria y Zootecnia, Universidad Nacional del Altiplano, Av. Floral 1153, Puno, Perú \\ d Aquainnovo, Cardonal S/N, Puerto Montt, Chile \\ e Núcleo Milenio INVASAL, Concepción, Chile
}

\section{A R T I C L E I N F O}

\section{Keywords:}

Bias

Pearson's correlation

Heritability

Oncorhynchus mykiss

\begin{abstract}
A B S T R A C T
The aim of this study was to compare the accuracy of breeding values (EBVs) predicted using the traditional pedigree based Best Linear Unbiased Prediction (PBLUP) and the single-step genomic Best Linear Unbiased Prediction (ssGBLUP) for resistance against infectious pancreatic necrosis virus (IPNV) in rainbow trout. A total of 2278 animals were challenged against IPNV and 768 individuals were genotyped using a $57 \mathrm{~K}$ single nucleotide polymorphism array for rainbow trout. Accuracies for both methods were assessed using five-fold crossvalidation. The heritabilities were higher for PBLUP compared to ssGBLUP. The ssGBLUP accuracies outperformed PBLUP in 7 and $11 \%$ for days to death and binary survival, respectively. The ssGBLUP could be an alternative approach to improve the accuracy of breeding values for resistance against infectious pancreatic necrosis virus in rainbow trout, using information from genotyped and non-genotyped animals.
\end{abstract}

\section{Introduction}

Infectious pancreatic necrosis virus (IPNV) has been recognized as a major viral disease problem in salmonids [1] and in the year of 2015 the IPN viral agent represented about $30 \%$ of the disease diagnoses in the salmon farming centers in Chile [52]. The IPNV is a member of the family Birnaviridae, a non-enveloped and double-stranded RNA viruses with a bi-segmented (A and B) genome encoding five or six proteins [2]. Typical strategies for controlling IPNV outbreaks include vaccines and husbandry measures [3]. Selective breeding can represent an alternative to control this disease in salmonids [4-6,51].

In Atlantic salmon (Salmo salar) large and significant genetic variation associated to IPNV mortality has been reported [1,7,8]. Moreover, a quantitative trait loci (QTL) with major effect on IPNV mortality in seawater and freshwater have been detected [9-12] and successfully used for marker-assisted selection (MAS) by breeding companies [13]. In rainbow trout (Oncorhynchus mykiss), significant genetic variation has been reported for IPNV resistance [14] and a marker with a moderate effect was found to be associated to this trait [15]. The lack of a
QTL with major effect suggests that MAS could not be the most appropriate method to incorporate genomic information to accelerate genetic improvement for IPNV resistance in the rainbow trout population used in the present study. As an alternative, genomic selection may be suggested to increase the genetic progress by using dense SNP genotypes [6].

The traditional pedigree best linear unbiased predictor (PBLUP) [16] is considered one of the preferred methods for the estimation of breeding values (EBV) and is commonly used for genetic evaluations in breeding programs in aquaculture species [17]. This approach uses all available information on relatives to predict EBV, by using the numerator relationship (A) matrix, while correcting for fixed, non-genetic effects and genetic trends in the population [18]. Recent theoretical and empirical studies indicate that replacing the A matrix by a genomic relationship (G) matrix, which requires genotypic information for all the phenotyped animals, can increase the accuracy of genetic evaluations for important economic traits in salmonids [19-28]. A common situation in fish breeding is that only a proportion of the phenotyped population is actually genotyped. As an alternative to incorporate all

\footnotetext{
* Corresponding author

E-mail address: jmayanez@uchile.cl (J.M. Yáñez).
} 
phenotyped animals into the genetic evaluation the single-step genomic best linear unbiased prediction (ssGBLUP) method has been proposed $[29,30]$. ssGBLUP can automatically account for all relatives (genotyped and non-genotyped animals), simultaneously fitting genomic information to estimate fixed effects and predict EBV, simplifying the practical implementation of genomic selection [30,31].

Recent studies have shown the benefits from the use of ssGBLUP in increasing the accuracy of genomic predictions for uniformity of body weight in Atlantic salmon [32], resistance against bacterial cold water disease [25,26] and resistance against Piscirickettsia salmonis [28] in rainbow trout. However, to date there are no studies comparing the use of the pedigree relationship (A) and a combined pedigree and genomics relationship $(\mathrm{H})$ matrix for predicting breeding values for one of the most important viral diseases affecting rainbow trout aquaculture, IPNV.

The objective of this study was to assess the accuracies of EBVs for resistance against infectious pancreatic necrosis virus using the traditional PBLUP and ssGBLUP methods in farmed rainbow trout.

\section{Material and methods}

\subsection{Phenotypes}

Phenotypic data for IPNV resistance in 2278 rainbow trout individuals (representing 58 maternal full-sib families and 20 paternal half-sib families) were obtained as described by Flores-Mara et al. [14]. The fish belonged to the 2014 year-class of the Aguas Claras S.A. breeding program (Puerto Montt, Chile), which has been selected for weight at harvest across three generations using best linear unbiased prediction (BLUP) approach. It has been recently reported that resistance against IPN and weight at harvest are not genetically correlated in this rainbow trout population [14]. The average body weight and age of fish was $2.24(\mathrm{SD}=0.71)$ grams and $154(\mathrm{SD}=15)$ days, respectively. The challenge was carried out in a recirculation system using a $0.25 \mathrm{~m}^{3}$ tank with fresh water. The average temperature, oxygen saturation and salinity during the experiment were $11{ }^{\circ} \mathrm{C}, 95.74 \%$ and $3.46 \mathrm{ppt}$, respectively. The IPN virus isolate (CD-AQ03; Sp serotype) was purchased from Centrovet Ltda. (Puerto Montt, Chile). The virus was isolated from infected Atlantic salmon kidney obtained from a Chilean farm located in the Xth Region, Chile, during an outbreak in November 2014. Isolation was carried out using CHSE-214 cell line and then cryopreserved until the preparation of inoculum in RTG-2 cell line [14]. The challenge was performed with a virus concentration of 107.82 $\mathrm{TCID}_{50} / \mathrm{mL}$, determined by the Karber-Spearman method [33]. The application of the inoculum was done by intraperitoneal route with $0.05 \mathrm{~mL}$ per fish. Additionally, $1.1 \mathrm{~L}$ of inoculum was diluted in $5 \mathrm{~L}$ of fresh water and then poured into the tank containing $130 \mathrm{~L}$ of fresh water at $17^{\circ} \mathrm{C}$ and kept at retained flow for $4 \mathrm{~h}$. After this, fresh water at $10^{\circ} \mathrm{C}$ was incorporated to induce thermal shock. The challenge test spanned 63 days and mortalities were recorded daily. The cause of death was confirmed by molecular diagnostics using RT-PCR. At the end of challenge test, all surviving fish were anesthetized and euthanized. Fin clip samples were taken from all animals for the DNA extraction. All the experimental challenge procedures were approved by The Comité Institucional de Cuidado y Uso de Animales (CICUA) from the University of Chile (Certificate $\mathrm{N}^{\circ} 17,019-\mathrm{VET}-\mathrm{UCH}$ ).

\subsection{Genotypes}

The genotyping strategy was aimed at maximizing the phenotypic variance within the sample while keeping a balanced representation of fish per family. Hence, genotyping was not totally random, but focused on selecting all susceptible fish $(\mathrm{n}=280)$ from the different families. The remaining fish $(n=488)$ were selected at random from the different families trying to keep similar number of animals per family. Thus, each family was represented within the sample with an average of
$13(\mathrm{SD}=2)$ fish/family.

Genomic DNA was extracted from fin clip samples from 768 fish using the commercial DNeasy Blood \& Tissue Kit, Qiagen, following the manufacturer's instructions. The fish were genotyped using an $57 \mathrm{~K} \mathrm{SNP}$ Affymetrix $^{\circledast}$ Axiom $^{\circledast}$, designed by The National Center for Cool and Cold Water Aquaculture, at the United States Department of Agriculture (USDA) and commercially available [34].

The genotypes were quality controlled using Affymetrix's Software AXIOM Analysis Suite using the default settings. Additional quality control steps were conducted by filtering out SNPs and sample with a Hardy-Weinberg equilibrium test $p$-value less than 0.00001, SNP call rate lower than 0.95 and a minor allele frequency lower than 0.01 .

\subsection{PBLUP and ssGBLUP methods}

The variance components and EBVs were initially predicted using the conventional pedigree-based BLUP (PBLUP) method, under the following model:

$\mathrm{y}=\mathrm{X} \beta+\mathrm{Za}+\mathrm{e}$

where $y$ is the vector of phenotypic observations (day to death or binary survival), $\beta$ is a vector of initial weight as co-variate, $a$ is a vector of random additive genetic polygenic effects with a distribution $\sim \mathrm{N}(0$, $A \sigma_{\mathrm{a}}{ }^{2}$ ), where $A$ is the pedigree relationship matrix and $\sigma_{a}^{2}$ is the additive genetic variance; $e$ is the vector of random error effects with a distribution $\sim \mathrm{N}\left(0, I \sigma_{\mathrm{e}}{ }^{2}\right)$, where $I$ is an identity matrix and $\sigma_{\mathrm{e}}{ }^{2}$ is the residual variance; and $X$ and $Z$ are the incidence matrices.

The PBLUP solutions for the breeding values were obtained using the mixed model equations [16]:

$\left[\begin{array}{cc}X^{\prime} X & X^{\prime} Z \\ Z^{\prime} X & Z^{\prime} Z+\alpha A^{-1}\end{array}\right]\left[\begin{array}{l}\hat{\beta} \\ \hat{a}\end{array}\right]=\left[\begin{array}{c}X^{\prime} y \\ Z^{\prime} y\end{array}\right]$

where $\hat{\beta}$ is the vector of fixed effect solutions, $\hat{a}$ is the vector of estimated breeding values, and $\alpha=\hat{\sigma}_{\mathrm{e}}^{2} / \hat{\sigma}_{\mathrm{a}}^{2}$. The genetic variance $\left(\hat{\sigma}_{\mathrm{a}}^{2}\right)$ and residual variance $\left(\hat{\sigma}_{\mathrm{e}}^{2}\right)$ were estimated using the restricted maximum likelihood (REML) method [35].

The variance components and genomic breeding value (GEBV) were also estimated using ssGBLUP method, using a similar model to the described above. Nevertheless, in ssGBLUP the kinship matrix is replaced by the $\mathrm{H}$ matrix [29], in which genotypes and pedigree data are combined. Thus, the inverse of the matrix $\mathrm{H}$ is:

$\mathrm{H}^{-1}=\mathrm{A}^{-1}+\left[\begin{array}{cc}0 & 0 \\ 0 & \mathrm{G}^{-1}-\mathrm{A}_{22}^{-1}\end{array}\right]$

Where, $\mathrm{A}^{-1}$ is the inverse numerator relationship matrix for all animals, $\mathrm{A}_{22}{ }^{-1}$ is the inverse of the pedigree-based relationship matrix for genotyped animals only; and $\mathrm{G}^{-1}$ is the inverse genomic relationship matrix.

The trait day to death was analyzed as a linear trait using AIREMLF90 and BLUPF90, whereas, the trait binary survival was analyzed as a threshold trait using THRGIBBS1F90b from BLUPF90 family programs [36].

Resistance to IPNV was measured as the challenge survival, defined as the number of days to death (DD), with values ranging from 13 to 63 days, and as binary survival (BS), scored as 1 if the fish died during the challenge test and 0 if the fish survived until the end of the challenge. In this study, the iteration process did not converge for binary survival, even using a large number of iteration $(5,000,000)$. In this way, we adjusted the binary survival as a linear trait.

\subsection{Prediction accuracy}

To compare the accuracy of genomic and pedigree-based predictions, a five-fold cross-validation scheme was applied as it has been previously described by Yoshida et al. [28]. Briefly, all phenotyped and genotyped animals $(n=2278)$ were randomly separated into five 
validations sets. The genomic predictions of the validation data sets were determined one at a time where the phenotypic records of $20 \%$ of the genotyped animals $(n=144)$ were set to missing and the remaining $80 \%$ of the genotyped fish $(n=577)$ plus $100 \%$ of the animals with only phenotypes $(n=1557)$ were used as training dataset.

Accuracy was used to assess the performance of each method and was estimated as follows:

$\mathrm{r}_{\mathrm{EBV}, \mathrm{BV}}=\frac{\mathrm{r}_{\mathrm{EBV}, \mathrm{y}}}{h}$

where $r_{\mathrm{EBV}}$, BV is the correlation between the EBV of a given model (predicted for the validation set using information from the training set) and $y$ is the recorded individual phenotype, while $h$ is the square root of the common heritability, calculated using PBLUP [37]. The Pearson's correlation and the regression between the EBVs obtained by PBLUP and GEBVs predicted with ssGBLUP in the validation data set were used to measure the degree of similarity between the predictions and as a measure to indicate the bias of predictions, respectively.

\section{Results}

The summary statistics for both traits, DD and BS, and the initial weight used as are presented in Table 1 . The cumulative mortality for all phenotyped fish at the end of challenge test was $12.3 \%$, ranging between $0 \%$ and $47.62 \%$ for the most resistant and the most susceptible family, respectively. The cumulative mortality for the genotyped fish at the end of challenge test was $34.5 \%$, ranging between $0 \%$ and $100 \%$ for the most resistant and the most susceptible family, respectively. The Fig. 1 shows the percentage of cumulative mortality per family.

A total of 38,292 markers and 721 samples passed on the filtering criteria. The heritabilities estimated for ssGBLUP method were lower (DD $=0.25$ and $\mathrm{BS}=0.24$ ) than those obtained with PBLUP (DD $=0.40$ and $\mathrm{BS}=0.35$ ) (Table 2).

Prediction accuracies based in five-fold cross-validations obtained with ssGBLUP were slightly higher than those obtained with PBLUP. The nominal difference in the prediction accuracy was 0.04 and 0.06 for DD and BS, respectively (Table 3). The relative increase in accuracies when comparing PBLUP against ssGBLUP was 7 and $11 \%$ for DD and BS, respectively. Moreover, for both methods (PBLUP and ssGBLUP) BS showed somewhat higher accuracies than DD. The slightly higher prediction accuracies using genomic information compared to the PBLUP, was probably due the small number of genotyped animals used in the validation set.

The Pearson's correlation between the PBLUP and ssGBLUP predictions were high and similar for both traits. The bias values were below the unity, and the value for BS was slightly lower than the one observed for DS (Table 4).

\section{Discussion}

The results for the pedigree-based estimates of heritability are consistent with previous studies conducted on the same rainbow trout population [14] and lower compared with the genomic heritability estimated by Rodríguez [15] using the genomic BLUP method [37]. In a

Table 1

Summary statistics for initial weight, day to death and survival to IPNV in rainbow trout.

\begin{tabular}{|c|c|c|c|c|c|c|c|c|}
\hline \multirow[t]{2}{*}{ Traits } & \multicolumn{5}{|c|}{ Phenotyped fish $\mathrm{N}=2278$} & \multicolumn{3}{|c|}{ Genotyped fish $N=721$} \\
\hline & Mean & SD & Min & Max & Mean & SD & Min & Max \\
\hline $\begin{array}{l}\text { Initial weight } \\
\text { (g) }\end{array}$ & 2.24 & 0.71 & 0.70 & 6.50 & 2.14 & 0.73 & 0.8 & 5 \\
\hline $\begin{array}{l}\text { Days to death } \\
\text { (days) }\end{array}$ & 57 & 9.44 & 13 & 53 & 52 & 13.99 & 13 & 53 \\
\hline Survival (\%) & 87.66 & - & - & - & 64.63 & - & - & - \\
\hline
\end{tabular}

previous study Vallejo et al. [25,26], found a lower heritability for resistance against bacterial cold water disease in rainbow trout when comparing ssGBLUP against PBLUP (for both trait definitions: days to death and binary survival), which is in agreement with our results.

Several studies for different traits and livestock species concluded that the single-step genomic evaluations provide more accurate prediction of the genetic merit than classical PBLUP method [38-41]. For Salmo salar, Sae-Lim et al. [32] found a relative increase prediction ability of $19 \%$ for uniformity and body weight when used the ssGBLUP compared to PBLUP. In a previous study for bacterial cold water disease resistance in rainbow trout, Vallejo et al. [25] observed a lower predicted ability for ssGBLUP compared to PBLUP for the trait measured as day to death using a small training sample size $(n=583)$ and progeny testing. In a second study using also progeny performance and a larger number of genotyped $(n=1473)$ and phenotyped $(n=7893)$ animals a considerable relative increase in the accuracy of GEBVs (near 80\%) was observed for ssGBLUP when compared to EBVs predicted using traditional pedigree-based BLUP [26]. The relatively moderate increase in accuracy when comparing PBLUP with ssGBLUP (7 to $11 \%$ for DD and $\mathrm{BS}$, respectively) found in the present study may have been affected by the low quantity of animals genotyped $(n=768)$. Furthermore, we also found a higher accuracy when analyzing IPNV resistance as a binary trait, as reported by Vallejo et al. [25], using a close number of genotyped animals.

High values for the Pearson's correlation coefficient for both traits indicate a high agreement between predictions from the ssGBLUP and PBLUP. Regarding bias, the ideal value is the unity, which indicates that there is no bias in the prediction [42,43]. Here we found bias values somewhat below the unity indicating overestimation of the EBVs and GEBVs. Vallejo et al. [25,26] obtained higher and similar level of bias for pedigree- and genomic-based genetic evaluations for bacterial cold water disease resistance in rainbow trout, respectively, when compared to the results presented here.

Different factors can influence the accuracy of genomic predictions, including the number of genotyped individuals, the number of individuals in the training population, the linkage disequilibrium between the SNP and all QTL controlling the traits and the level of relatedness among the animals in training and validation set [44-47]. Some studies in Atlantic salmon reported that genomic predictions can accelerate the genetic progress for disease resistance traits when compared against pedigree-based method $[19,20,24,48]$. In addition, some of these studies have shown that using lower-density panels $(0.5$ to $10 \mathrm{~K}$ ) were sufficient to maximize the increase in accuracy, suggesting that decreasing marker density could help to reduce the genotyping costs without compromising the gain in accuracy [19,20]. A recent study shown that the use of low density SNP panels combined with genotype imputation strategies can provide a cost effective approach for the practical implementation of genomic selection in salmon [49]. In the present study, we found an increase in prediction accuracy when comparing ssGBLUP against PBLUP, even though we used a relatively reduced number of genotyped animals with a $57 \mathrm{~K}$ commercial SNP panel. In addition, the cumulative mortality for the whole population was low (12.3\%), which decreased the amount of variation to be exploited by different genetic evaluation methods and most likely had an impact on reducing the accuracy of predictions. The results presented here suggest that the ssGBLUP can be a promising alternative to improve the accuracy of genetic merit prediction for IPN resistance in rainbow trout when information of pedigree, phenotypes and a reasonable number of genotypes are available. Further studies, using a higher number of both genotyped and phenotyped animals, in addition to the use of alternative designs to evaluate prediction accuracies (e.g. progeny testing) are needed in order to know if the differences in the prediction accuracy between PBLUP and ssGBLUP presented here can be even larger. Moreover, an economic analysis should be considered to determine if such increases in prediction accuracies can justify the cost of different SNP genotyping strategies for the practical implementation 
(a)
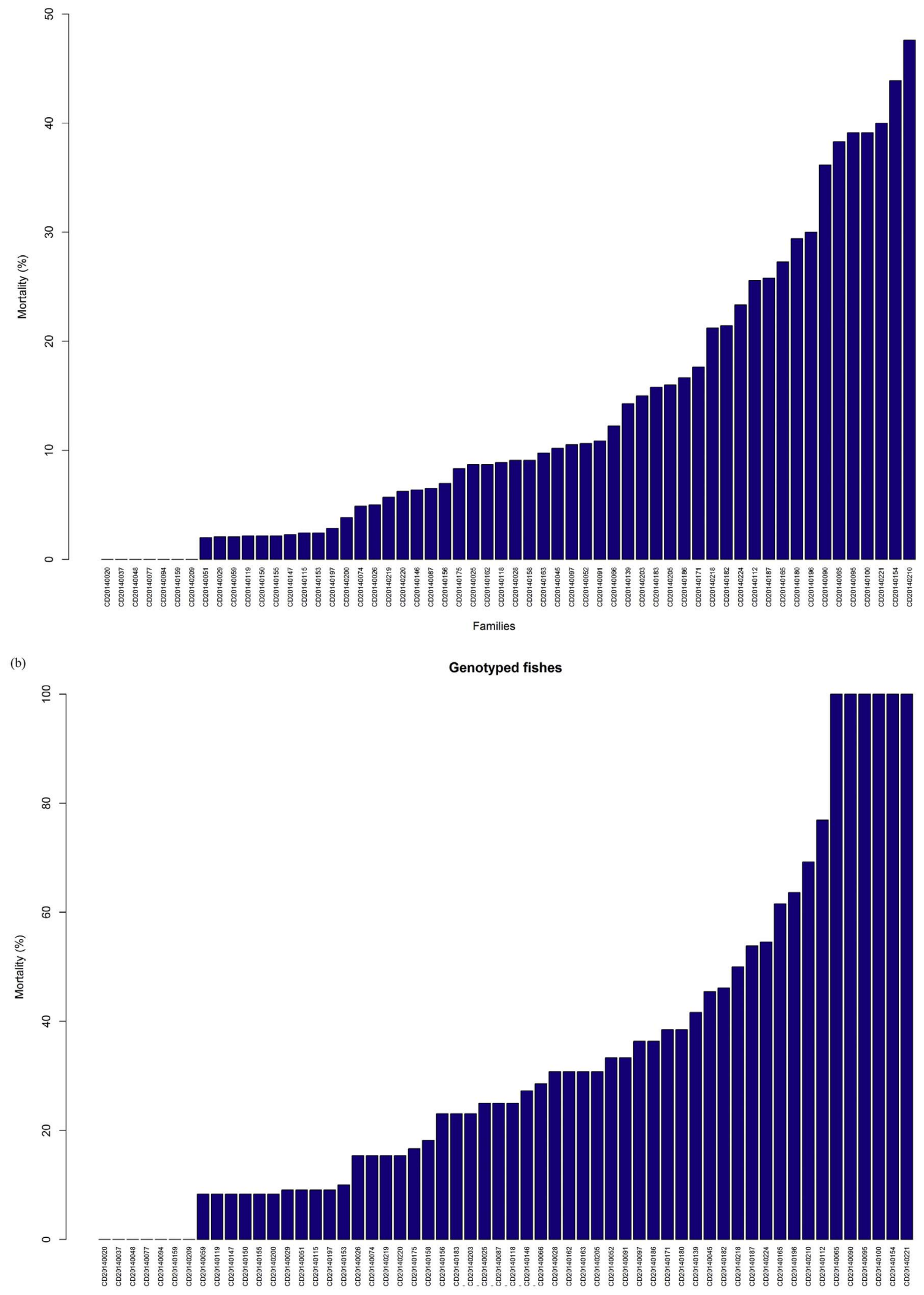

Phenotyped fishes

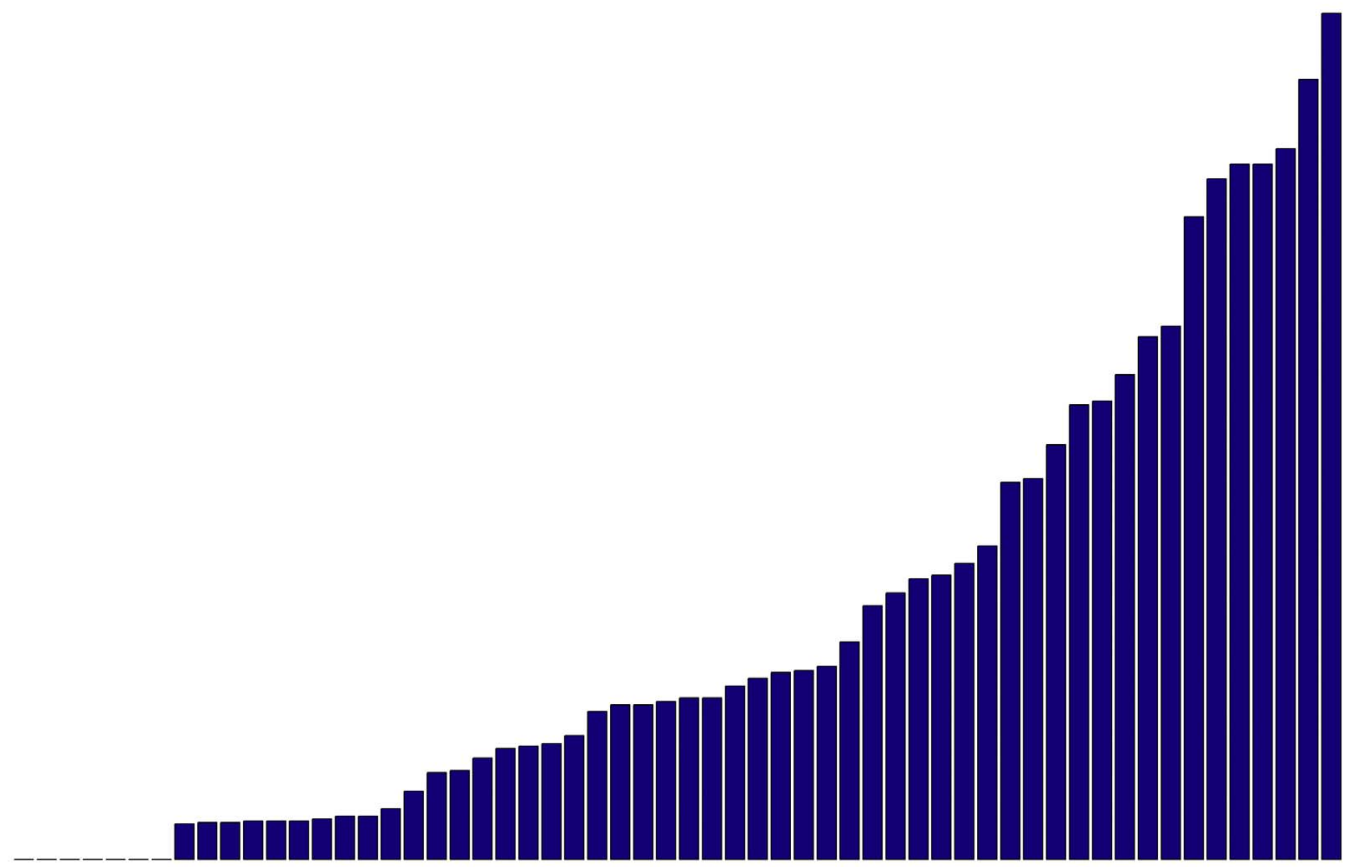

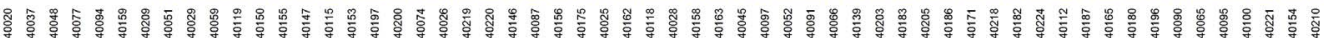

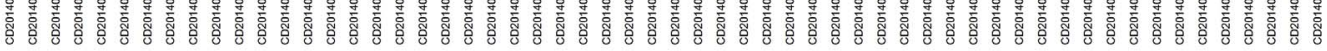

Families

Genotyped fishes

Families

Fig. 1. Percentage of cumulative mortality by family after 63 days challenge test against IPNV in rainbow trout for phenotyped animal (a) and genotyped (b). 
Table 2

Variance components and standard error (in parenthesis) for days to death (DD) and binary survival (BS) after a challenge against IPNV for rainbow trout using pedigree based BLUP (PBLUP) and single-step genomic BLUP (ssGBLUP).

\begin{tabular}{llll}
\hline Trait & $\boldsymbol{\sigma}_{\mathbf{g}}^{2 \mathrm{a}}$ & $\sigma_{\mathrm{e}}{ }^{2 \mathrm{~b}}$ & $\boldsymbol{h}^{2 \mathrm{c}}$ \\
\hline PBLUP & & & \\
DD (days) & $38.01(9.34)$ & $56.90(5.44)$ & $0.40(0.08)$ \\
BS (0 or 1) & $0.03(0.01)$ & $0.06(0.01)$ & $0.35\left(0.08^{\mathrm{d}}\right)$ \\
SsGBLUP & & & \\
DD (days) & $21.27(4.53)$ & $65.18(3.32)$ & $0.25(0.05)$ \\
BS (0 or 1) & $0.02(0.00)$ & $0.07(0.00)$ & $0.24\left(0.04^{\mathrm{d}}\right)$
\end{tabular}

a Genetic variance.

b Residual variance.

c Heritability.

d Standard deviation.

Table 3

Five-cross validation accuracies for days to death (DD) and binary survival (BS) after an IPNV challenge in rainbow trout.

\begin{tabular}{llllll}
\hline \multirow{2}{*}{ Model } & \multicolumn{2}{l}{ DD } & & & \multicolumn{2}{l}{ BS } \\
\cline { 2 - 3 } \cline { 5 - 6 } & Average & $\mathrm{SD}^{\mathrm{a}}$ & & Average & $\mathrm{SD}^{1}$ \\
\hline PBLUP & 0.49 & 0.06 & & 0.50 & 0.05 \\
ssGBLUP & 0.53 & 0.07 & & 0.56 & 0.08 \\
\hline
\end{tabular}

${ }^{\text {a }}$ Standard deviation.

Table 4

Five-fold cross-validation means (standard deviation) for Pearson's correlation (above diagonal) and bias (below diagonal) for days to death (DD) and binary survival (BS) to IPNV in rainbow trout.

\begin{tabular}{llllll}
\hline Trait & DD & & & BS \\
\cline { 1 - 2 } \cline { 5 - 6 } Model & PBLUP & ssGBLUP & & PBLUP & ssGBLUP \\
\hline PBLUP & - & $0.92(0.01)$ & & - & $0.92(0.01)$ \\
ssGBLUP & $0.89(0.03)$ & - & & $0.86(0.02)$ & - \\
\hline
\end{tabular}

of genome-enabled selection for IPN resistance in rainbow trout breeding populations.

\section{Conflicts of interest}

The authors declare that they have no conflict of interest.

\section{Acknowledgements and funding}

The Aguas Claras providing funding for the experimental challenge test and the fish used in this study. This work has been partially funded by a grant from CORFO (11IEI-12843) and Núcleo Milenio INVASAL from Iniciativa Científica Milenio (Ministerio de Economía, Fomento y Turismo, Gobierno de Chile). GMY acknowledge Fundação de Amparo à Pesquisa do Estado de São Paulo (FAPESP processes numbers 2014/ 20626-4 and 2015/25232-7) for fellowship. RC acknowledge for CNPq fellowship (process 308636/2014-7).

\section{References}

1] A. Rønneseth, H.I. Wergeland, M. Devik, $\emptyset$. Evensen, E.F. Pettersen, Mortality after IPNV challenge of Atlantic salmon (Salmo salar L.) differs based on developmental stage of fish or challenge route, Aquaculture 271 (2007) 100-111, http://dx.doi. org/10.1016/j.aquaculture.2007.03.021.

[2] N.M. Ruane, S.J. McCleary, L.J. McCarthy, K. Henshilwood, Phylogenetic analysis of infectious pancreatic necrosis virus in Ireland reveals the spread of a virulent genogroup 5 subtype previously associated with imports, Arch. Virol. 160 (2015) 817-824, http://dx doi.org/10.1007/s00705-014-2307-9.

[3] R.J. Roberts, M.D. Pearson, Infectious pancreatic necrosis in Atlantic salmon, Salmo salar L, J. Fish Dis. 28 (2005) 383-390, http://dx.doi.org/10.1111/j.1365-2761. 2005.00642.x.

[4] J. Ødegård, M. Baranski, B. Gjerde, T. Gjedrem, Methodology for genetic evaluation of disease resistance in aquaculture species: challenges and future prospects, Aquac. Res. 42 (2011) 103-114, http://dx.doi.org/10.1111/j.1365-2109.2010.02669.x.

[5] J.M. Yañez, V. Martínez, Factores genéticos que inciden en la resistencia a enfermedades infecciosas genetic factors involved in resistance to infectious diseases in salmonids and their application in breeding programmes, Arch. Med. Vet. 13 (2010) 1-13, http://dx.doi.org/10.4067/S0301-732X2010000200002.

[6] J.M. Yáñez, R.D. Houston, S. Newman, Genetics and genomics of disease resistance in salmonid species, Front. Genet. 5 (2014) 1-13, http://dx.doi.org/10.3389/fgene. 2014.00415.

[7] D.R. Guy, S.C. Bishop, J.A. Woolliams, S. Brotherstone, Genetic parameters for resistance to infectious pancreatic necrosis in pedigreed atlantic salmon (Salmo salar) post-smolts using a reduced animal model, Aquaculture 290 (2009) 229-235, http://dx.doi.org/10.1016/j.aquaculture.2009.02.015.

[8] M. Wetten, T. Aasmundstad, S. Kjøglum, A. Storset, Genetic analysis of resistance to infectious pancreatic necrosis in Atlantic salmon (Salmo salar L.), Aquaculture 272 (2007) 111-117, http://dx.doi.org/10.1016/j.aquaculture.2007.08.046.

[9] A.A. Gheyas, R.D. Houston, J.C. Mota-Velasco, D.R. Guy, A.E. Tinch, C.S. Haley, J.A. Woolliams, Segregation of infectious pancreatic necrosis resistance QTL in the early life cycle of Atlantic Salmon (Salmo salar), Anim. Genet. 41 (2010) 531-536, http://dx.doi.org/10.1111/j.1365-2052.2010.02032.x.

[10] R.D. Houston, A. Gheyas, A. Hamilton, D.R. Guy, A.E. Tinch, J.B. Taggart, B.J. McAndrew, C.S. Haley, S.C. Bishop, Detection and confirmation of a major QTL affecting resistance to infectious pancreatic necrosis (IPN) in Atlantic salmon (Salmo salar), Dev. Biol. (Basel) 132 (2008) 199-204.

[11] R.D. Houston, C.S. Haley, A. Hamilton, D.R. Guy, A.E. Tinch, J.B. Taggart, B.J. McAndrew, S.C. Bishop, Major quantitative trait loci affect resistance to infectious pancreatic necrosis in Atlantic salmon (Salmo salar), Genetics 178 (2008) 1109-1115, http://dx.doi.org/10.1534/genetics.107.082974.

[12] R.D. Houston, C.S. Haley, A. Hamilton, D.R. Guy, J.C. Mota-Velasco, A.A. Gheyas, A.E. Tinch, J.B. Taggart, J.E. Bron, W.G. Starkey, B.J. McAndrew, D.W. VernerJeffreys, R.K. Paley, G.S.E. Rimmer, I.J. Tew, S.C. Bishop, The susceptibility of Atlantic salmon fry to freshwater infectious pancreatic necrosis is largely explained by a major QTL, Heredity (Edinb). 105 (2010) 318-327, http://dx.doi.org/10. 1038/hdy.2009.171.

[13] T. Moen, J. Torgersen, N. Santi, W.S. Davidson, M. Baranski, J. Ødegård, S. Kjøglum, B. Velle, M. Kent, K.P. Lubieniecki, E. Isdal, S. Lien, Epithelial cadherin determines resistance to infectious pancreatic necrosis virus in Atlantic salmon, Genetics 200 (2015).

[14] R. Flores-Mara, F.H. Rodríguez, R. Bangera, J.P. Lhorente, R. Neira, S. Newman, J.M. Yáñez, Resistance against infectious pancreatic necrosis exhibits significant genetic variation and is not genetically correlated with harvest weight in rainbow trout (Oncorhynchus mykiss), Aquaculture 479 (2017) 155-160, http://dx.doi.org/ 10.1016/j.aquaculture.2017.05.042.

[15] F.H. Rodríguez Huanca, Identificación de marcadores SNP (polimorfismo de nucleótido único) asociados a la resistencia frente al virus de la necrosis pancreática infecciosa (IPN) en truchas arcoíris (Oncorhynchus mykiss), Universidad de Chile, 2017.

[16] C.R. Henderson, Applications of linear models in animal breeding, Appl. Linear Model. Anim. Breeding, 1984.

[17] T. Gjedrem, M. Baranski, Selective Breeding in Aquaculture: an Introduction, Reviews: Methods and Technologies in Fish Biology and Fisheries, Springer, Netherlands, Dordrecht, 2009, http://dx.doi.org/10.1007/978-90-481-2773-3.

[18] B.W. Kennedy, Use of mixed model methodology in analysis of designed experiments, Advances in Statistical Methods for Genetic Improvement of Livestock, Springer, Berlin, Heidelberg, 1990, pp. 77-97, http://dx.doi.org/10.1007/978-3642-74487-7_5.

[19] R. Bangera, K. Correa, J.P. Lhorente, R. Figueroa, J.M. Yáñez, Genomic predictions can accelerate selection for resistance against Piscirickettsia salmonis in Atlantic salmon (Salmo salar), BMC Genomics 18 (2017) 121, http://dx.doi.org/10.1186/ s12864-017-3487-y.

[20] K. Correa, R. Bangera, R. Figueroa, J.P. Lhorente, J.M. Yáñez, The use of genomic information increases the accuracy of breeding value predictions for sea louse (Caligus rogercresseyi) resistance in Atlantic salmon (Salmo salar), Genet. Sel. Evol. 49 (2017) 15, http://dx.doi.org/10.1186/s12711-017-0291-8.

[21] M. Lillehammer, T.H.E. Meuwissen, A.K. Sonesson, A low-marker density implementation of genomic selection in aquaculture using within-family genomic breeding values, Genet. Sel. Evol. 45 (2013) 39, http://dx.doi.org/10.1186/12979686-45-39.

[22] J.F. Taylor, Implementation and accuracy of genomic selection, Aquaculture 420-421 (2014) S8-S14, http://dx.doi.org/10.1016/j.aquaculture.2013.02.017.

[23] H.Y. Tsai, A. Hamilton, A.E. Tinch, D.R. Guy, K. Gharbi, M.J. Stear, O. Matika, S.C. Bishop, R.D. Houston, Genome wide association and genomic prediction for growth traits in juvenile farmed Atlantic salmon using a high density SNP array, BMC Genomics (2015) 1-9, http://dx.doi.org/10.1186/s12864-015-2117-9.

[24] H.-Y. Tsai, A. Hamilton, A.E. Tinch, D.R. Guy, J.E. Bron, J.B. Taggart, K. Gharbi, M. Stear, O. Matika, R. Pong-Wong, S.C. Bishop, R.D. Houston, Genomic prediction of host resistance to sea lice in farmed Atlantic salmon populations, Genet. Sel. Evol. 48 (2016) 47, http://dx.doi.org/10.1186/s12711-016-0226-9.

[25] R.L. Vallejo, T.D. Leeds, B.O. Fragomeni, G. Gao, A.G. Hernandez, I. Misztal, T.J. Welch, G.D. Wiens, Y. Palti, Evaluation of genome-enabled selection for bacterial cold water disease resistance using progeny performance data in rainbow trout: insights on genotyping methods and genomic prediction models, Front. Genet. 7 (2016) 1-13, http://dx.doi.org/10.3389/fgene.2016.00096. 
[26] R.L. Vallejo, T.D. Leeds, G. Gao, J.E. Parsons, K.E. Martin, J.P. Evenhuis, B.O. Fragomeni, G.D. Wiens, Y. Palti, Genomic selection models double the accuracy of predicted breeding values for bacterial cold water disease resistance compared to a traditional pedigree-based model in rainbow trout aquaculture, Genet. Sel. Evol. 49 (2017) 17, http://dx.doi.org/10.1186/s12711-017-0293-6.

[27] S. Vela-Avitúa, T.H. Meuwissen, T. Luan, J. Ødegård, Accuracy of genomic selection for a sib-evaluated trait using identity-by-state and identity-by-descent relationships, Genet. Sel. Evol. 47 (2015) 9, http://dx.doi.org/10.1186/s12711-0140084-2.

[28] G.M. Yoshida, R. Bangera, R. Carvalheiro, K. Correa, R. Figueroa, J.P. Lhorente, J.M. Yáñez, Genomic prediction accuracy for resistance against Piscirickettsia salmonis in farmed rainbow trout, G3 (Bethesda) 8 (2017) 1-8 (g3.300499.2017), https://doi.org/10.1534/g3.117.300499.

[29] I. Aguilar, I. Misztal, D.L. Johnson, A. Legarra, S. Tsuruta, T.J. Lawlor, Hot topic: a unified approach to utilize phenotypic, full pedigree, and genomic information for genetic evaluation of Holstein final score, J. Dairy Sci. 93 (2010) 743-752, http:// dx.doi.org/10.3168/jds.2009-2730.

[30] A. Legarra, O.F. Christensen, I. Aguilar, I. Misztal, Single step, a general approach for genomic selection, Livest. Sci. 166 (2014) 54-65, http://dx.doi.org/10.1016/J. LIVSCI.2014.04.029.

[31] D.A.L. Lourenco, I. Misztal, S. Tsuruta, I. Aguilar, E. Ezra, M. Ron, A. Shirak, J.I. Weller, Methods for genomic evaluation of a relatively small genotyped dairy population and effect of genotyped cow information in multiparity analyses, J. Dairy Sci. 97 (2014) 1742-1752, http://dx.doi.org/10.3168/jds.2013-6916.

[32] P. Sae-Lim, A. Kause, M. Lillehammer, H.A. Mulder, Estimation of breeding values for uniformity of growth in Atlantic salmon (Salmo salar) using pedigree relationships or single-step genomic evaluation, Genet. Sel. Evol. 49 (2017) 33, http://dx. doi.org/10.1186/s12711-017-0308-3.

[33] M.A. Hamilton, R.C. Russo, R.V. Thurston, Trimmed Spearman-Karber method for estimating median lethal concentrations in toxicity bioassays, Environ. Sci. Technol. 11 (1977) 714-719, http://dx.doi.org/10.1021/es60130a004.

[34] Y. Palti, G. Gao, S. Liu, M.P. Kent, S. Lien, M.R. Miller, C.E. Rexroad, T. Moen, The development and characterization of a $57 \mathrm{~K}$ single nucleotide polymorphism array for rainbow trout, Mol. Ecol. Resour. 15 (2015) 662-672, http://dx.doi.org/10. 1111/1755-0998.12337.

[35] H.D. Patterson, R. Thompson, Recovery of inter-block information when block sizes are unequal, Biometrika 58 (1971) 545, http://dx.doi.org/10.2307/2334389.

[36] I. Misztal, S. Tsuruta, Manual for BLUPF90 Family of Programs, (2015).

[37] P.M. VanRaden, Efficient methods to compute genomic predictions, J. Dairy Sci. 91 (2008) 4414-4423, http://dx.doi.org/10.3168/jds.2007-0980.

[38] C.Y. Chen, I. Misztal, I. Aguilar, S. Tsuruta, T.H.E. Meuwissen, S.E. Aggrey, T. Wing, W.M. Muir, Genome-wide marker-assisted selection combining all pedigree phenotypic information with genotypic data in one step: an example using broiler chickens, J. Anim. Sci. 89 (2011) 23-28, http://dx.doi.org/10.2527/jas.2010-3071.

[39] D.G.M. Gordo, R. Espigolan, R.L. Tonussi, G.A.F. Júnior, T. Bresolin, A.F.B. Magalhães, F.L. Feitosa, F. Baldi, R. Carvalheiro, H. Tonhati, H.N. de
Oliveira, L.A.L. Chardulo, L.G. de Albuquerque, Genetic parameter estimates for carcass traits and visual scores including or not genomic information, J. Anim. Sci. 94 (2016) 1821, http://dx.doi.org/10.2527/jas.2015-0134.

[40] A. Onogi, A. Ogino, T. Komatsu, N. Shoji, K. Simizu, K. Kurogi, T. Yasumori, K. Togashi, H. Iwata, Genomic prediction in Japanese Black cattle: application of a single-step approach to beef cattle, J. Anim. Sci. 92 (2014) 1931-1938, http://dx. doi.org/10.2527/jas.2014-7168.

[41] R.M.O. Silva, B.O. Fragomeni, D.A.L. Lourenco, A.F.B. Magalhães, N. Irano, R. Carvalheiro, R.C. Canesin, M.E.Z. Mercadante, A.A. Boligon, F.S. Baldi, I. Misztal, L.G. Albuquerque, Accuracies of genomic prediction of feed efficiency traits using different prediction and validation methods in an experimental Nelore cattle population, J. Anim. Sci. 94 (2016) 3613, http://dx.doi.org/10.2527/jas.2016-0401.

[42] H.H. Neves, R. Carvalheiro, A.M. O Brien, Y.T. Utsunomiya, A.S. do Carmo, F.S. Schenkel, J. Sölkner, J.C. McEwan, C.P. Van Tassell, J.B. Cole, M.V. da Silva, S.A. Queiroz, T.S. Sonstegard, J.F. Garcia, Accuracy of genomic predictions in Bos indicus (Nellore) cattle, Genet. Sel. Evol. 46 (2014) 17, http://dx.doi.org/10.1186/ 1297-9686-46-17.

[43] M.F.R. Resende, P. Muñoz, M.D.V. Resende, D.J. Garrick, R.L. Fernando, J.M. Davis, E.J. Jokela, T.A. Martin, G.F. Peter, M. Kirst, Accuracy of genomic selection methods in a standard data set of loblolly pine (Pinus taeda L.), Genetics 190 (2012).

[44] H.D. Daetwyler, B. Villanueva, J.A. Woolliams, L. Schaeffer, A. Crawford, Accuracy of predicting the genetic risk of disease using a genome-wide approach, PLoS One 3 (2008) e3395, http://dx.doi.org/10.1371/journal.pone.0003395.

[45] H.D. Daetwyler, R. Pong-Wong, B. Villanueva, J.A. Woolliams, The impact of genetic architecture on genome-wide evaluation methods, Genetics 185 (3) (2010) 1021-1031.

[46] M. Goddard, Genomic selection: prediction of accuracy and maximisation of long term response, Genetica 136 (2009) 245-257, http://dx.doi.org/10.1007/s10709008-9308-0.

[47] Y.C.J. Wientjes, P. Bijma, R.F. Veerkamp, M.P.L. Calus, An equation to predict the accuracy of genomic values by combining data from multiple traits, populations, or environments, Genetics 202 (2) (2016) 799-823.

[48] J. Ødegård, T. Moen, N. Santi, S.A. Korsvoll, S. Kjøglum, T.H.E. Meuwisse, Genomic prediction in an admixed population of Atlantic salmon (Salmo salar), Front. Genet. 5 (2014) 1-8, http://dx.doi.org/10.3389/fgene.2014.00402.

[49] H.-Y. Tsai, O. Matika, S.M. Edwards, R. Antolín-Sánchez, A. Hamilton, D.R. Guy, A.E. Tinch, K. Gharbi, M.J. Stear, J.B. Taggart, J.E. Bron, J.M. Hickey, R.D. Houston, Genotype imputation to improve the cost-efficiency of genomic selection in farmed Atlantic salmon, G3 Genes Genomes Genet. 7 (2017).

[51] J.M. Yáñez, S. Newman, R.D. Houston, Genomics in aquaculture to better understand species biology and accelerate genetic progress, Front. Genet. 6 (2015) 1-3, http://dx.doi.org/10.3389/fgene.2015.00128.

[52] Sernapesca, Informe sanitario de salmonicultura en centros marinos año 2015, Servicio Nacional de Pesca y Acuicultura, Departamento de salud animal, 2016http://www.sernapesca.cl/index.php?option = com_remository\&Itemid $=246$ \&func $=$ fileinfo\&id $=14754 /$, Accessed date: 22 May 2017. 